\title{
Economics and Culture
}

\author{
Iwan J Azis* \\ Cornell University \& University of Indonesia, Indonesia
}

Submission: December 19, 2018; Published: June 11, 2019

*Corresponding author: Iwan J Azis, Cornell University \& University of Indonesia, Indonesia

"if we learn anything from the history of economic development, it is that culture makes all the difference" (David Landes: "Max Weber was right on")

Abstract

The notion that something cannot be measured does not exist seems to apply in the absence of culture in economics where the role of institutions is at the center of the link between the two. Yet, any economic prosperity, crisis, or deprivation, are the results of human behavior reflecting the outcome of social learning-a central concept of culture. Institutions and culture interact and evolve in a complementary way. They can affect the process of exchange and the transaction costs, which in turn determine the economic performance. Although more work has been done to understand better the interrelation between economics and culture, most remain fell on deaf ears among mainstream economists even though real world cases have shown the critical role of such an interrelation. The deficiency of mainstream economics that overlooks the role of culture and institutions is shown in this paper.

\section{Introduction}

Following the tradition of the marginalist school, abstraction in economics received a big push during the late 19th century led by Stanley Jevons and Auguste Walras. This happened despite Adam Smith's strong feeling for the significance of culture and Malthus' deep sense about how culture affects the dynamics of population. David Ricardo was the most instrumental in reducing economics to a culturally free abstraction. Alfred Marshall, at least judged from his early work, was another culprit although his subsequent Industry and Trade shows an increased awareness towards the complex cultural reality behind the abstraction of supply and demand, inserting a strong institutional flavor in the analysis.

This is rather puzzling because the core part of economics is exchange, and the terms that permit the exchange is called the terms of trade, the ratio of the price producers are willing to receive and consumers to pay for the exchange. Indeed, while exchange is a fundamental part of economic behavior, perhaps except for game theory and transaction cost theory, remarkably little attention has been given in the economic literature to analysis of processes of exchange. Thorbecke \& Cornelisse [1]. argued that the item exchanged, the actors engaged in the decisions, and the physical, social, technological, and legal environment within which the actors operate in the exchange, matter in understanding the different transactions and outcomes. The combination of those elements, the formation process of the exchange, and the resulting transaction is considered an exchange configuration.

Mainstream economists contend when there is a divergence between the equilibrium price and the actual price at which the exchange takes place, either excess demand or excess supply will be eliminated by price changes. But the actual process of adjustment in the exchange is not satisfactorily explained despite the fact that in reality the whole process captures the satisfaction of those who trade, which is a complex subject to understand but is necessarily an integral part of any set of cultural relations involving things like trust, regret, deception, persuasion, and learning process.

In this paper, I intend to show the deficiency of mainstream economics that overlooks the role of culture and institutions. The latter should be an integral part of economics. Aside from the difficulty to identify the relation and causality between culture, institutions and economic performance, some work has been done in this area although much of it still fell on deaf ears among mainstream economists.

\section{Mainstream and Cultural Economics}

Despite their arguments that clearly foreshadow the cultural economics, it is unclear why institutionalists like Thorstein Veblen (in the US) and Max Weber (in Europe) failed to influence the mainstream of economics during the time. Indeed, one of the critical questions in cultural economics is about the extent to which a system of institutions that produce changes in culture will survive or fail precisely because of such changes. Theoretically, it is the institutional system of legitimacy that will survive and dominate, not the dynamics of power and wealth; without legitimacy neither power nor wealth can be preserved.

Perhaps nothing more obvious than in monetary economics where the use of formalistic mechanical models is prerequisite and with almost a complete lack of interest on the cultural aspects within which the institutions of money and banking operate. The models are filled with statistics and causation (often confused 
with correlation) with little attempt to open the lid to see what the actual processes are. This is irrespective of the fact that one cannot really learn about what is going on in the banking sector unless we treat bankers as human beings and try to understand how they really think. The same applies to players in the capital market.

The departure from partial equilibrium to general equilibrium in economics is another example of a neglect of cultural dimension. While the overall quantities produced and consumed are correctly not taken as the result of individual producers and consumers' decisions, rather the result of the interactions of such decisions, it is often assumed in the corresponding models that the choices of diverse agents can be represented by the choices of one "representative" utility-maximizing individual whose choices coincide with the aggregate choices. The heterogeneity in behavior and culture is considered irrelevant. This is clearly unjustified and ill-suited for studying problems involving coordination failures such as unemployment, under-utilization, financial instability, etc.

For most mainstream economists, when things get more complex, and interdependence amplifies, new variables, parameters and equations are added, and non-linearity is introduced, expecting that the model's predictive power will strengthen. Little efforts are made to delve into the changing patterns of behavior as part of the possible mutations in social system where the process of selection may involve increased vulnerabilities, bankruptcies, crisis, or simply a loss of legitimacy.

Even in taxation where the system emerges from the interaction of different governmental subcultures, and where the tax system itself is the result of a long historical process involving changing culture of governments, members of parliament, and the constituents, the efficiency of "one-way transfer" depends not only on the perception of threat (sanctions of the law if failing to pay tax) but also the culture of tax collectors. The mass of individuals paying taxes with a fair degree of fidelity itself is clearly a cultural phenomenon. Yet, most research on tax issues tends to be exclusively financial and economic-based, void of any cultural context.

The picture could be less grim as some fields of economics have come close to cultural economics, although they are more of the business schools' domain, e.g., marketing, industrial organization, and labor economics where there is a long tradition in the study of collective bargaining, labor unions, culture of the factory, etc. The bad news is, even in these fields mechanistic approaches have encroached the analysis to the point where no collaborative work with sociologists, anthropologists, and psycho-sociologists is considered necessary.

Yet, in the supply-demand theory, for example, when excess supply occurs, producers may alter their preference by staying away from efficiency efforts, and consumers may not follow the standard law of supply-demand as they do not raise consumption despite the downward pressure on the price. In such circumstances, preferences should not be taken only as the determinant of the economic process like in a standard optimization model, instead it should be learned during the process of cultural transformation. Thus, the culture-affected learning process could generate outcome different from a standard solution.

The emphasis on learning is the most crucial difference between mechanistic economics and cultural economics, implying that cultural economics is evolutionary in nature. Learning is part of social evolution that is more complex than biological evolution. It occurs more slowly because people, let alone societies, are not easily willing to change due to their realistic appraisal of the uncertainties arising from such a change, which is a standard problem in economic development.

In contrast, mechanistic economics relies on its predictive power based on the derived parameters (assumed stable) of difference or differential equations, which contradicts with the fact that in any dynamic process, when strain increases the parameters in the system change. More importantly, the implied adjustment may create further strain in the same part or in other parts of the system. If a crisis eventually occurs, the absence of stability (order) with constant parameters may not tell us much about the stability that is absent. Even if no adjustment is taking place, something important about the social system may have been generated by the absence of such adjustment: what does not happen can be more interesting than what does.

\section{Which Causes Which}

Like in any relation between two components, the third, fourth and other components may have some roles as intermediate variables. This applies to the link between culture and economic performance as well. Then there is a common problem concerning the direction of causality.

On the first issue, at the outset one needs to define what is culture and what is economic performance. Various narratives for culture have been proposed, from which the following elements are relevant: customary beliefs and values, preferences, long duration of consistency in cultural traits and groups, be it social, ethnic or religious-based. The relevant elements in economic performance are level and growth of output or income, savings, and income distribution. In some cases, the probability of something positive to emerge is also used, such as having a greater number of entrepreneurs.

Intermediate components relevant for identifying the link between culture and economic performance include priorbeliefs, religions, ethnicities, preferences, and trust. Individually they may not have an independent role, but they can function as a coordinating device to make societies play the same "game" to different conditions and focal points.

The importance of prior beliefs cannot be overstated as many decisions-thus the corresponding outcome and performanceare based on such priors (e.g., which technology to use, what measures to mitigate the effects of climate change, how to deal with different economic shocks, what strategy to cope with ageing population). Here culture plays a major role in forming individual 
beliefs even in the new environment and several generations later. Thus, prior beliefs can be an important channel of culture influence on economic performance. Yet, economists generally do not have much say about priors. They typically assume that individuals have common priors.

Trust is considered an important component arising from priors. Many even believe that it is through the concept of trust that culture enters the economic discourse. Several researches have been done to demonstrate the contribution of the level of trust of a community to economic performance [2-4], although most do not elaborate the mechanism through which measured trust is positively correlated with economic performance. What remains debatable is whether trust is an inherited cultural variable or is developed through the adoption of a proper legal system. Some also argue that trust is the outcome of individuals or societies' interactions.

The significance of trust in economics is made clearer by Arrow [5]. "Virtually every commercial transaction has within itself an element of trust, certainly any transaction conducted over a period of time." International trade is an example of area where trust matters a lot. But it was the seminal work of Putnam $[6,7]$ that put trust at the center of the discussion by considering it as a form of social capital capturing the value and relationships of resources where social networks play a central role in the production of public and common good. The constituent elements of social capital, over which people have more control than over culture, are trust, norms, and networks.

In the current era of information technology (IT), priors including trust can be influenced or enhanced by the availability of information ('big data, 'internet of things' and all that). Examples of on-line trade and transactions abound where reviews and reputation may alter the beliefs of people or customers. Even in political elections the use of 'big data' combined with complex algorithm has been widespread, and it proves effective.

The problems with causality are no less critical than the definitional issue. The first problem is the difficulty to separate culturally based beliefs from rational expectations. Whether trust is culturally driven or rational prior driven by environment with a prevailing degree of trustworthiness is not easy to determine. It is generally the case that the idiosyncratic component of trust tends to increase when societies share the same cultural trait (e.g., religion), and decreases with the genetic distance in terms of ancient cultural aspects. The level of education also matters: the role of inherited cultural aspects in the formation of priors tends to diminish as society gets more educated (reduced dependence of trust on cultural variables).

Even if cultural variables and measures of economic performance are highly correlated, that does not necessarily mean one causes the other. Two events occur simultaneously does not imply causality.

Another serious conundrum is with regards to the direction of causality, or what econometricians label endogeneity problem: "which affects which." The debate about whether culture affects economics or vice versa has a long history. Some proposed that technology determines the type of social structure and dominant culture. In supporting the argument that steam-mill produces capitalism, Karl Marx [8] held that view. In contrast, Max Weber [9] and Polanyi et al. [10] had the opposite line of thinking. To the extent the cultural aspect like religion is considered important to the establishment of markets as well as in moderating market excesses, they argued that culture-in this case religion--played a critical role in the development of capitalism. Their explanations are powerful, and the examples provided are quite persuasive. Yet, they fell on deaf ears among mainstream economists.

As expected, each camp attempted to get their idea vindicated. Economists of the Chicago school tried hard to endogenize beliefs and preferences [11]. Some went further by showing that religious and social norms are the result of a group-level optimization. Others extended the theory of human capital by emphasizing investment in social skills and social interactions. Those who were more econometrically inclined emphasized the use of proper econometric techniques to identify the direction of causality, among others by employing a set of intermediate variables as the "instrumental variables," or by looking at historical exogenous shocks in their models. But the existence of complementarities between culture and economic performance often hinders identification.

While differences between the two camps may never been reconciled, active debates on the link between culture and economics continue. Most of the debates put the emphasis on the interaction between culture and institutions.

\section{Role of Institutions}

Institutions are meant to facilitate human interaction by providing patterns that will regulate society's behavior [12-14]. It is the "rules of the game in a society" by promoting certain behaviors and prohibit other behaviors. There are formal institutions (e.g., bank regulation, tax system, accounting rules) and informal institutions (e.g., codes of conduct, habits, traditions, norms). While most analyses focus on the former, the latter can be more important for understanding its role to shape economic performance. Enforcement is another critical component of institutions. Even well-established rules and regulations can be rendered ineffective if enforcement is weak. Two systems with similar institutions may produce different economic performance because of different enforcement.

To the extent formal and informal institutions are shaped by ideas and ideologies, not created in a vacuum, culture enters the equation. Through culture-affected ideas, individuals use their subjective mental constructs to interpret the world around them and make choices. Arguably, institutions determine the extent that ideas and ideologies, hence culture, matters.

Informal institutions come from 'socially transmitted information' and are part of the heritage or culture. In the case of formal institutions, they are also linked with the prevailing political 
system. For example, in federalism markets are fostered through competition for economic organizations at the sub-national level. In other systems, the room for pleasing powerful interest group may be more ample. The resulting economic performance under different systems (hence different institutional arrangements) is likely dissimilar. In this respect, the resulting economic performance can be associated with the efficiency of the outcome.

Contrary to the neo-classical economic theory, negotiations required to reach an efficient outcome are not costless. For example, there are costs for learning (by consumers) about the quality--and eventually the price--of goods to be exchanged. It may take some time before the actual exchange occurs. There can be also a bargaining process as part of negotiations. This also entails costs.

The problem of information asymmetry can make the observed costs deviate from the true costs, making them more difficult to measure. Even if both parties are honest, there is always something with respect to enforcing the agreement that still needs to be specified either implicitly or explicitly. This is also not costless. When a dispute arises and a settlement (requiring lawyers) is needed, the costs can further multiply.

All the above costs are known as the transaction costs, usually high and not always reported (not internalized) especially in many developing countries. In some cases, personalized transactions are still the rule rather than exception. High transactions costs lead to unfavorable economic performance. Since only at zero transaction costs an efficient outcome can prevail [15], attempts to lower transaction costs are preferred, a most common of which is through establishing clear property rights (also often deficient in many developing countries) to facilitate the smooth functioning of markets.

High transaction costs can also be linked to the size of the unproductive informal sector. Small business operations and poor individuals including poor migrants are "forced" to remain small and informal. The transaction costs for entering the formal sector are too high, i.e., getting permits which also requires paying bribery, not to mention time-consuming. Unsecured assets and a lack of formal documents also diminish their incentives to expand, and bank credits are difficult to get under such circumstances. Thus, informality persists. So do inefficiency and low productivity [16].

In a dynamic context, an institutional framework ensuring that technology can be advanced ('creative destruction') is also frequently absent in developing countries. Free-entry and free-exit hardly prevail. Firms with a privileged access to those in power survive by patronage through monopoly rights, soft budgets, or special concessions. For them no innovation is needed to survive. More seriously, they resent any policy measures intended to enable innovation to raise productivity when those measures threaten their survival. Power influence enables them to do so and to keep away from potential competitors.
In short, culture-influenced institutions can affect transaction costs, and in turn economic performance in a static and a dynamic sense. The latter works through organizations' decisions about technology and innovation [17].

It is important to note that one cannot claim the superiority of causality direction between institutions and culture because the two interact and evolve in a complementary way. The relation also involves mutual feedback effects: depending on the type of institutions culture may evolve in differing ways, and different culture may cause institutions to function differently $[18,19]$.

In this context, a more relevant economic performance is productivity. While it is less directly observable compared to standard variables like output and income, productivity involves attributes highly relevant to cultural traits and cultural capital, particularly the social capital.

In The prosperous communities, Putnam (1993) argued that social capital is like "physical capital and human capitaltools and training that enhance individual productivity." He went on to describe that social capital refers to "features of social organization, such as networks, norms, and trust, that facilitate coordination and cooperation for mutual benefit." The description is unarguably loaded with important implications [20].

By giving the 'same status' like other traditional inputs (capital and labor), social capital contributes to productivity through a production-function setting used extensively by economists. It also highlights the significance of individuals' "participation" that will form group's ability to work jointly through "collaborative effort" as capital. Failure to do so will result in a disappointing "productivity performance." Absent of trustful relation, the system tends to focus on "short-term self-interest" and individual transactions, eliminating the potentials and opportunities for accumulation and "innovation" process like in a standard capital theory. While networks of institutions are important, their presence in no way assures collaboration when "commitment and coordination" is limited. This translates into obstacles for many developing and emerging markets where weak capacity, including the State capacity to from a "coalition building" needed for "institutional upgrading" to support innovation must face a "growing and diverse power of influence among social groups and business communities."

All the above requisites and conditions (in quotation marks) reflect the institutional quality and social capital, which, through the implied transaction costs will determine the extent to which a country is able to sustain productivity growth to improve society's welfare [21].

\section{Summary}

Culture and economics are closely linked. Yet, economists have long been reluctant to study the interrelation between the two. This is partly because a testable hypothesis with measured data that can be proven or disproven is hard to construct, let alone the difficulty to define the term 'culture.' This is unfortunate as it 
reflects the notion that something cannot be measured does not exist.

Faced with reality of more complex relations and growing interdependence, mainstream economists opt for adding new variables, parameters and equations. When pressed further, they introduce non-linearity in the model. Little efforts are made to delve into the behavior that reflects the outcome of social learning-a central concept of culture--where a set of cultural relations involving learning process as part of social evolution, which is more complex than biological evolution, matters. The emphasis on learning implies that unlike mechanistic economics the cultural economics is evolutionary in nature.

The role of institutions is at the center of the link between culture and economics, particularly on the direction of causality. Institutions and culture interact and evolve in a complementary way, not a one-way causality. Culture-influenced institutions can affect transaction costs, and in turn economic performance. In a dynamic setting, through organizations' decisions about technology and innovation, a set of requisites reflecting the institutional quality and social capital has an important role to influence productivity growth hence society's welfare. One of such requisites is individuals' participation that will form group's ability to work jointly through collaborative effort. The required trustful relation is in sharp contrast with the short-term selfinterest driven transactions.

Although more and more work has been done to understand better the interrelation between economics and culture, albeit deficient of the mechanism, most fell on deaf ears among mainstream economists. It is mind-boggling how economics can be reduced to a culturally and institutionally free abstraction when abundant evidence indicates real world cases have shown otherwise.

\section{References}

1. Cornelisse PA, E Thorbecke (2010) Exchange and Development, Edward Elgar, Cheltenham, UK.

2. La Porta R, de Silanes FL, Shleifer A, Vishny RW (1997) Trust in large organizations. American Economic Review 87(2): 333-338.

3. La Porta R, de Silanes FL, Shleifer A, Vishny RW (1999) The quality of government. Journal of Law Economics and Organization 15(1): 222279.

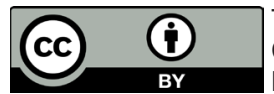

This work is licensed under Creative Commons Attribution 4.0 License DOI: 10.19080/ASM.2019.03.555617
4. Stephen K, Zak PJ (2001) Trust and Growth. Economic Journal 111(470): 295-321.

5. Arrow KJ (1972) Gifts and Exchanges. Philosophy and Public Affairs 1(4): 343- 362.

6. Putnam R (1993) Making Democracy Work. Princeton University Press, Princeton, NJ.

7. Putnam Robert D (2000) Bowling Alone: The Collapse and Revival of American Community. New York and London: Simon and Schuster. UK.

8. Karl M (1859) A Contribution to the Critique of Political Economy, International Publishers, New York.

9. Max W (1905) The Protestant Ethic and the Spirit of Capitalism, Routledge Classic, London, UK.

10. Polanyi K, Arensberg C, Pearson H (1957) Trade and Market in the Early Empires: Economies in History and Theory. Reprinted in 1971 Chicago: Henry Regnery Company, USA.

11. George JS, Becker GS (1977) De Gustibus Non-Est Disputandum, The American Economic Review 67(2): 76-90.

12. North DC (1990) Institutions, Institutional Change and Economics, Cambridge University Press, Cambridge, UK.

13. Iwan JA (2000) "Institutions Matter," in Pers \& May Revolution, Gramedia, Indonesia.

14. Iwan (2008) Institutional Constraints and Multiple Equilibria in Decentralization. Review of Urban and Regional Development Studies 20(1): $22-33$

15. Coase RH (1960) Problem of Public Costs. Journal of Law and Economics 3: 144-171.

16. Besley TS, Coate S (1999) The Public Critique of Welfare Economics: An Exploration. NBER Working Papers 7083, National Bureau of Economic Research, Inc., Cambridge, MA, USA

17. Easterly W, Ross L (2002) Tropics, Germs, and Crops: How Endowments Influence Economic Development. NBER Working Papers 9106, National Bureau of Economic Research, Inc., Cambridge, MA, USA.

18. Henry PB, C Miller (2008) Institutions vs. Policies: A Tale of Two Islands. NBER Working Paper No. 14604, December, National Bureau of Economic Research, Inc., Cambridge, MA, USA.

19. Daniel K, Knetsch JL, Thaler RH (1986) Fairness and the Assumptions of Economics. The Journal of Business 59(4): S285-S300.

20. Rodrik D, Subramanian A, Trebbi F (2002) Institutions Rule: The Primacy of Institutions over Geography and Integration in Economic Development," NBER Working Paper No. 9305, October. Cambridge, MA, USA.

21. Shleifer A, Vishny RW (1993) Corruption the Quarterly Journal of Economics 108(3): 599-617.

\begin{tabular}{l} 
Your next submission with Juniper Publishers \\
will reach you the below assets \\
- Quality Editorial service \\
- Swift Peer Review \\
- Reprints availability \\
- E-prints Service \\
- Manuscript Podcast for convenient understanding \\
- Global attainment for your research \\
- Manuscript accessibility in different formats \\
( Pdf, E-pub, Full Text, Audio) \\
- Unceasing customer service \\
Track the below URL for one-step submission \\
https://juniperpublishers.com/online-submission.php \\
\hline
\end{tabular}

